\title{
A INSTITUCIONALIZAÇÃO DA PEDOLOGIA COMO CIÊNCIA POR FRIEDRICH ALBERT FALLOU - O CASO BRASILEIRO
}

\author{
Carlos Roberto ESPINDOLA
}

\begin{abstract}
RESUMO
O resgate da "história da ciência do solo" é realizado principalmente no âmbito da pedogênese, a partir da evolução das classificações taxonômicas. Desde a primeira metade do século XIX, naturalistas se interessaram por uma sistematização dos estudos sobre solos, que justificasse a criação de uma ciência autônoma, o que veio a ser proposto pelo alemão Friedrich Albert Fallou (1794-1877), com o termo "Pedologia". Entretanto, Fallou empregou nomes de solos extraídos das formações geológicas e das localidades de suas ocorrências, sendo criticado por não desenvolver uma classificação genética. Isso foi resolvido pelo russo V.V. Dokuchaev, que também adotou a mesma denominação, e por isso ganhou a paternidade desta ciência, o que foi contestado por diversos cientistas. Em 2008, com a tradução para o francês, a obra de Fallou passou a ser mais conhecida, reacendendo esta polêmica. Até 1960, a denominação dos solos no Brasil teve influência significativa de Fallou, como evidenciada pelo forte emprego de denominações geológicas.
\end{abstract}

Palavras-chave: história da pedologia, pioneirismo de Fallou, taxonomia antiga de solos.

\begin{abstract}
THE INSTITUTIONALIZATION OF PEDOLOGY AS A SCIENCE BY FRIEDRICH ALBERT FALLOU - THE BRAZILIAN CASE. The recovery of the "history of soil science" has been mainly carried out via pedogenesis, based on the evolution of taxonomic soil classifications. Ever since the early nineteenth century, naturalists have been interested in the systematization of soil studies in order to justify the creation of an autonomous science, which came to be proposed by the German F.A. Fallou, with the term "Pedology". However, he used soil names based on geological formations and locations of their occurrence, which resulted in his being criticized for not developing a genetic classification. This problem was solved by the Russian V.V. Dokuchaev, who adopted the same name (pedology) for soil sciences and thus gained the title of father of this science, although not without the protests of several scientists. In 2008 the work of Fallou became better known when it was translated into French, thereby reigniting this controversy. Until 1960, the denomination of soils in Brazil was significantly influenced by Fallou, as is evident from the strong employment of geological denominations.
\end{abstract}

Keywords: history of pedology, Fallou pioneering, ancient soil taxonomy.

\section{INTRODUÇÃO}

Nas diversas obras que tratam da história da ciência do solo tem sido recorrente a menção de que a introdução do vocábulo "pedologia" se deva ao alemão Friedrich Albert Fallou (1794-1877), originalmente um advogado bem sucedido, até passar a interessar-se por peculiaridades da superfície da terra, registradas na sua primeira publicação na idade de 51 anos (FELLER et al. 2008).
Nos 25 anos finais de sua existência consagrou-se às pesquisas científicas regionais (FALLOU 1855,1875 , dentre outras); a de cunho mais universal abordou os Fundamentos da Ciência do Solo (FALLOU 1857), porém a obra mais impactante foi Pedologie oder allgemeine und besondere Bodenkunde (Pedologia ou Ciência do Solo geral e especial), na qual advoga a necessidade de uma ciência específica para tratar dos solos (FALLOU 1862). 
Uma justificativa muito judiciosa para aquela pretensão era a de que a pedologia - já com esta denominação - representava a soma de conhecimentos resultantes da observação e exame do solo de maneira ordenada, dotada de um plano consequente na apresentação dos dados, de modo sintético e coerente, distinto do usual.

Com a posterior emergência formal de uma ciência independente gerada com o clássico trabalho sobre o Chernozém (terras negras), pelo russo DOKUCHAEV (1883), que houve por bem denominar pedologia, nada mais natural do que diversos cientistas se manifestassem a respeito da real "paternidade" deste ramo da ciência do solo.

\section{O CONHECIMENTO DOS SOLOS ATRAVÉS DOS TEMPOS}

$\mathrm{O}$ interesse pelo solo sempre esteve presente desde os primórdios da civilização, sob vários pontos de vista, quer como meio de produção de alimentos, registro do passado ou como uma das forças da natureza, com sua beleza mística e pleno de forças ligadas à vida e à morte (BUOL et al. 1973).

Na China, há 4 ou 5 mil anos, existem menções sobre as classificações de terras de acordo com a produtividade das colheitas. Por volta de 400 a.C., a importância do solo para as plantas foi comparada, por Hipócrates, à do estômago para os animais (SIMONSON 1968). A evolução das civilizações sempre foi acompanhada da importância conferida ao solo no sustento aos seres vivos (SCARPONI 1949).

Durante a gestão do império romano com Nero, Lucius Moderatus Columella relacionou seis tipos de solos com base nos padrões de suas coberturas vegetais, e Virgílio destacou as "terras negras" da Itália como as mais produtivas (PLAISANCE \& CAILLEUX 1958). A Columella se atribui a primeira teoria científica sobre fertilidade do solo, no ano 42 do século I (SALTINI 1984).

No século XVI, Bernard de Palissy (15101590) e Olivier de Serres (1539-1619) desenvolveram notáveis pesquisas voltadas aos solos e nutrição de plantas (BOULAINE \& MOREAU 2002); ambos relacionaram 19 caracteres necessários à descrição completa de um solo, sem qualquer hierarquia ou sistemática precisa (DEMOLON 1949).

No longínquo ano de 1740, o notório botânico taxonomista Lineu (Carl Linnaeus) mencionou a influência do solo no desenvolvimento das culturas em sua "Phylosophia Botanica"; em 1751, além da sistemática vegetal, empregou também uma maneira pessoal de classificar solos e minerais (YARILOV 1910).
Desde aquele século, eminentes cientistas despontaram defendendo notáveis polêmicas sobre a importância do húmus versus minerais na nutrição de plantas, dentre os quais Wallerius, Thäer, Müller e Liebig, que adicionaram conhecimentos fundamentais sobre fertilidade dos solos (FELLER et al. 2006).

Cientistas alemães já dominavam muitos conhecimentos sobre os solos (mineralogia, química, sobretudo da matéria orgânica) muito antes de Fallou, não sistematizados numa ciência, mas num mero "estudo do solo" - "Bodenkunde", conforme praticado, por exemplo, por HUNDESHAGEN (1830). Esta preocupação com a forma científica era defendida por SPRENGEL (1837), que incluía, além disso, o ensino, conforme seu "guia para análise química dos solos aráveis". O termo "Geologia Agrícola" servia também para permear estudos dessa natureza, conforme empregado por Rissler, em 1855, no título geral dos quatro volumes de "Introdução à agricultura comparada" (PÉDRO 1984a).

Charles Darwin, além de enaltecer a importância do húmus produzido por minhocas (mould), esboçou um corte vertical de solo esquematizando camadas diferenciadas - A-B-C-D (DARWIN 1838, 1881); não lhe passou despercebido um alinhamento horizontal de cascalhos, que JOHNSON (1989) atribui à primeira referência a uma possível stone line.

Contudo, se grande parte dessas pesquisas estava inserida numa "química agrícola" ou numa "geologia agrícola", a distribuição espacial dos solos era considerada nos mapeamentos geológicos como os de HITCHCOCK (1838), em Massachussets, que associou solos arenosos, barrentos, argilosos, calcários, de idade terciária e alúvios aos distintos substratos; análogo procedimento foi tomado por HILGARD (1860) no Mississipi, no seu "agricultural soil survey"; na Alemanha, uma das modalidades de classificação sugeridas por RICHTOFEN (1886) associava geologia e geografia.

FALLOU (1862) discriminou uma ciência do solo teórica - a pedologia, e uma ciência do solo agronômica prática - a agrologia, o que lhe garantiu, por parte da quase totalidade dos cientistas de diversos países, a condição de introdutor da denominação "pedologia" para o campo da ciência do solo que ele próprio concebera como "a soma de conhecimentos decorrentes da observação e exame do solo apresentados de uma maneira ordenada, sintética e coerente". PÉDRO (1984b) cogitou, entretanto, que o termo teria sido por ele retomado de SPRENGEL (1837). 


\section{A PATERNIDADE DA PEDOLOGIA NA VI- SÃO DOS PESQUISADORES}

Entretanto, o início da cristalização de uma ciência autônoma, com denominação própria, emersa da geologia e reconhecida pela maioria da comunidade científica internacional, deu-se com o russo DOKUCHAEV (1879), com o conceito de perfil de solo numa concepção genética, formado por camadas em evolução - os horizontes, em resposta à alteração de uma rocha-mãe numa determinada posição topográfica, sofrendo a ação do clima e de organismos ao longo do tempo. O solo popularizado como Chernozém serviu para embasar tais proposições (DOKUCHAEV 1883), assim como o Podzol da região de Smolensk, com seus destacados horizontes.

Não obstante o acolhimento majoritário desta nova ciência pela comunidade internacional - a "pedologia", o título de "fundador" ou "pai" da ciência pedológica atribuído a Dokuchaev foi posteriormente questionado por determinados cientistas, incluindo alguns próximos da sua equipe de trabalho, como YARILOV (1904); o antigo mestre da pedologia alemã moderna, RAMANN (1905), enfatizou ter sido Fallou o verdadeiro fundador desta ciência.

Também JOFFE (1929) assim se posicionou, mas comentou o fato de a classificação de Fallou não ter sido estritamente genética, o que pode ter concorrido para que sua obra tenha sido relegada pelos diversos pesquisadores. Por sua vez, a menção de HUMBOLDT \& BOUPLAND (1879), nas viagens do primeiro ao continente americano: "descubra um tipo de solo e um certo tipo de planta, e você encontrará um certo tipo de rocha", na visão de WILDE (1963), bastaria para lhe creditar o papel de fundador da pedologia. EHWALD (1960) também estabeleceu paralelos entre Humboldt e Dokuchaev nessa questão.

Esta polêmica sobre a "paternidade" da pedologia é frequentemente retomada entre os cientistas, tal como abordado amplamente por FELLER $e t$ al. (2008), com argumentos apresentados sob pontos de vista variados, às vezes retomando antigas posições, porém mais reforçadas. SCHROEDER (1988), entre outros, argumenta que a referência de Dokuchaev a Fallou bastaria para garantir a este a condição de fundador da pedologia. Em oposição, BLUME (2002) voltou a insistir que a classificação de Fallou era estritamente baseada nos substratos geológicos, ou seja, não genética. Em apoio, TANDARICH et al. (2002) reforçam que o perfil, como unidade de estudo do solo, apenas foi introduzido na pedologia genética russa.

A ausência explícita do quesito perfil foi contestada por ASIO (2005), ao comentar que Fallou o considerara de modo implícito, acreditando até que isso deva ter influenciado tanto Dokuchaev como Orth, este um dos primeiros a empregarem perfis para agrupar solos. JOHNSON et al. (2005) minimizaram esta influência, argumentando que Fallou mal enfocou o Chernozém em sua obra, pondo até em dúvida se o pesquisador russo teria verdadeiramente lido o seu trabalho.

Estranho é que até o ano 2008 ainda não se dispunha de uma tradução da obra de FALLOU (1862) em francês ou inglês, quando pesquisadores da França e da Suíça, em conjunto, cobriram esta lacuna, ao darem início a uma rigorosa tradução francesa, a iniciar pelo Prefácio e Sumário dos Capitulos (FELLER et al. 2008), com a observação de que a identificação de precursores maiores de uma matéria é sempre motivo de arrebatamento pelos historiadores.

Exemplificando esta ponderação, o grau de importância das pesquisas sobre matéria orgânica dado pelo dinamarquês P.E. Müller, de 1879 e 1887, serviria para credenciá-lo ao título de " $\mathrm{co}$ fundador do pensamento pedológico", no mesmo nível de Dokuchaev (FELLER et al. 2005). Todavia, no caso específico de Fallou, os tradutores admitem a dificuldade de se distinguir claramente entre "precursores" e "fundadores". Procurando diferenciá-los de modo genérico, colocaram como primeiro nível de constatação o claro esclarecimento do objeto central, ou seja, se o solo foi tomado como um corpo natural independente; caso positivo, poder-se-ia eventualmente, mas não necessariamente (em conformidade com os dados e suas interpretações), atribuir ao pesquisador a categoria de "cofundador", como nos casos de Fallou, Müller e Hilgard.

Não sendo o solo o objeto central, mesmo quando em certas passagens de uma notável pesquisa o investigador empregar algum enfoque pedogenético, é mais conveniente considerá-lo como "precursor", caso típico de Charles Darwin, a quem YARILOV (1936) chegou a atribuir a desígnia "fundador" da pedologia. Entretanto, no caso particular de Fallou, ser precursor, fundador ou cofundador de uma ciência reveste-se do mesmo grau de importância em termos históricos, para FELLER et al. (2008). 


\section{EXCERTOS DA TRADUÇÃO FRANCESA "PEDOLOGIE..."}

\subsection{Concepção geral da obra de Fallou pelo próprio autor}

É surpreendente que o homem, desde tempos imemoriais, tenha mostrado pequena preocupação com o que a agricultura possa provocar no solo, de elevada suscetibilidade a modificações. Por ser a mais a jovem de todas as ciências, é de estranhar que ela não tenha ainda se tornado uma disciplina de ensino científico. Os tratados e manuais a esse respeito são geralmente compilações de conteúdos de geologia, geografia, química agrícola e fisiologia vegetal, acrescidos do desmatamento, avaliação de terras, uso e conservação do solo, sem limites que possibilitem distinguir solo e terra arável (cultivada).

Ao conceber a pedologia como soma de conhecimentos da observação e análise do solo que resultam num modelo organizado, ela se diferencia de uma enciclopédia de economia, de uma liturgia do solo ou de um ensino de economia agrícola, sem ainda permitir que se coloque em prática os conhecimentos da ciência do solo. Se fosse repetir o que as obras existentes fazem, tal trabalho resultaria completamente inútil; por esta razão é necessário dar a ele precisão para que mereça a denominação ciência.

Todavia, nesta fase inicial do trabalho, as bases e princípios gerais foram apenas esboçados, devendo avançar na descrição dos tipos de solos aos moldes das ciências naturais, ainda amplamente desconhecida pelos agrônomos. Iniciar-se-á por uma ciência do solo geral, abordando a terminologia atinente à natureza e composição do sistema, sua estratificação e distribuição.

Inicialmente, o solo será descrito em seu todo, para depois esmiuçar as suas partes, numa concepção de ciência independente, na tentativa de abrir uma nova via que outros possam seguir e aperfeiçoar, propondo até uma nova maneira de ensiná-la, embasada em outros princípios e estilos de apresentação e emprego, a fim de que a atual menosprezada ciência do solo possa vir a merecer a honra de ser reconhecida como uma ciência.

Vários aspectos tradicionais desses estudos foram propositalmente omitidos, como também erros aceitos como verdade e transmitidos nos manuais vigentes, por não se pretender conduzir a matéria à costumeira polêmica quando um determinado manual refuta outro. Como os embates entre os especialistas não serão lidos pelos estudantes, é necessário que lhes sejam propiciadas condições para que, por opiniões próprias, possam decidir livre e independentemente sobre os argumentos apresentados.

Incursões no passado, como determinadas explicações geológicas, facilitam a compreensão do texto, ainda que não indispensáveis, na esperança de que não sejam rejeitadas como inúteis ou supérfluas. Acima de tudo, roga-se ponderar que abrir uma nova via não é uma tarefa fácil, por ser possível restarem dúvidas e direcionamentos mais adequados. Com isso, o autor espera um julgamento imparcial às suas proposições.

\subsection{Tópicos do conteúdo (adaptada e simplificada)}

$1^{a}$ PARTE - Ciência do solo geral - "Conhecimento fundamental do solo", composta dos 8 (oito) Capítulos numerados a seguir.

1 - Gênese (fragmentação, dissolução, deslocamentos e deposições pela água e pelo ar, inundações); 2 - Estado do solo (componentes orgânicos e inorgânicos; partículas; solos gerados e aluviões); 3 - Natureza do solo (propriedades gerais e particulares); 4 - Espaço do solo (posição e profundidade; regiões dos solos gerados e dos aluviões e seus limites); 5 - Estratificação (rocha-mãe, arranjamento, segregação e inversões dos estratos); 6 - Diferenças entre os solos (demonstração de diferenças gerais e especiais entre os solos); 7 - Classificação (agrícola e natural; denominações científicas e classificação mineralógica dos tipos de solos); 8 - Delimitação dos solos.

$2^{a}$ PARTE - Ciência do solo em particular - "Conhecimento dos tipos de solos em particular" ("caracterização natural"), com duas Classes - "Terras de solos gerados" e "Terras de aluviões" e respectivos "Gêneros".

$1^{a}$ Classe - Terras de solos gerados - "Tipos particulares de solos"

$1^{\circ}$ Gênero - Solos de rochas quartzosas 1. Solos de rocha quartzosa: a- Solo de quartzito; b- Solo silicoso. 2. Solos de rochas conglomeráticas de quartzo: a- Vermelhos; b- Cinzas. 3. Solos de rochas de areias de quartzo: a- Solo de pedras de cantaria, com a Variedade "Solo de rocha arenosa do Jura e de Leia"; b- Solo de rocha arenosa de Grauwack; c- Solo de rocha arenosa de Kauper, com a Variedade "Solo multicor"; d- Solo vermelho de rocha arenosa.

$2^{\circ}$ Gênero - Solos de rochas argilosas: aSolo de argila ou de pórfiro; b- Solo de argila e de xisto; c- Solo de xisto de Grauwack; d- Solo de 
xisto de Thourmergel (Variedade "Solo de xisto e de greda").

$3^{\circ}$ Gênero - Solos de rochas micáceas: aSolo de xisto micáceo; b- Solo de gnaisse; c- Solo de xisto de mica calcária; d- Solo de xisto clorado.

$4^{\circ}$ Gênero - Solos de rochas feldspáticas: aSolo de granito; b- Solo de granulito (Variedade "Solo de gnaisse félsico"); c- Solo de scheelita; dSolo de traquito; e- Solo de fonólito.

$5^{\circ}$ Gênero - Solos de rochas calcárias ou de talco calcário: a- Solo de calcário do Jura e de calcário de conchas (Variedade "Solo de calcário conglomerático, greda e calcário de Plän"); b- Solo de dolomita do Jura (Variedade "Solo de dolomita de Zechstein").

$6^{\circ}$ Gênero - Rochas com augita e hornblenda: a- Solo de basalto (Variedade "Solo de basalto conglomerático, lava basáltica e dolerito"); b- Solo de diabásio; c- Solo de serpentina.

$2^{a}$ Classe - Terras de Aluviões

$1^{\circ}$ Gênero - Solos de seixos: 1. Solo de areia silicosa. 2. Solo de areia silicatada: a- Solo de assoreamento com seixos comuns (Variedade "Solo de areia cascalhenta, de conchas e cascalhos rolados"); b- Solo compacto de areia de silicato ou de seixos (Variedade "Solo compacto de areia cascalhenta ou de seixos").

$2^{\circ}$ Gênero - Solos de marga: a- Solo de marga calcária; b- Solo de marga de argila; c- Solo de marga de areia (Variedade "Solo de areia dcascalhenta"); d- Solo de marga de talco ou de loess.

$3^{\circ}$ Gênero - Solos de limo (silte): a- Solo de limo comum (Variedades "limo de argilomineral e limo de mica"); b- Solo de greda argilosa).

$4^{\circ}$ Gênero - Solos de turfa: a- Solo de turfa argilosa; b- Solo de turfa limosa; c- Solo de turfa calcária (Variedade "Solo de turfa de Escher, Schlier e de loess"); d- Solo de turfa arenosa.

Seção Especial - Adições ocasionais no solo: 1. Depósitos de escórias e cinzas vulcânicas. 2. Blocos rochosos desmoronados e encostas deprimidas. 3. Deposições fluviais acumuladas. 4. Turfeiras infiltradas e acumuladas nas superfícies.

Concluída a tradução francesa, os autores mencionam que o fato de a matéria ter sido escrita antes de 1862 - há mais de 20 anos da publicação da obra usualmente tomada como referência para o ingresso da pedologia como ciência autônoma (o Chernozém russo, por DOKUCHAEV 1883) - é mais que meritório o atendimento ao apelo de Fallou para um "julgamento imparcial" do seu trabalho (FELLER et al. 2008).

\section{REFLEXOS DA OBRA DE FALLOU NA PE- DOLOGIA BRASILEIRA}

O início de um estudo organizado dos solos no Brasil, sobretudo com respeito à terminologia, teve início na Bahia, com os "Elementos de Agrologia" produzidos por D'UTRA (1897), que se valeu de um corte vertical dividido em "solo arável" - terras argilosas, arenosa, calcárias e humíferas e "subsolo" terroso e rochoso, atribuindo ao conjunto denominações populares como massapé.

Um antigo registro significativo para a história da nossa pedologia é a matéria produzida para o "Primeiro Congresso de Ensino Agrícola", em 1911, em São Paulo - "Noções de Agrologia", contendo tópicos como origem e constituição dos solos, classificação da terra arável, propriedades físicas e químicas dos solos, entre outros (SÃO PAULO 1911).

$\mathrm{Na}$ terceira década do século passado, os pesquisadores Theodureto de Camargo e o alemão Paul Vageler do Instituto Agronômico de Campinas/SP, alimentaram o estudo científico dos nossos solos, após atividades desenvolvidas junto à escola Dokuchaev, onde privaram, dentre vários cientistas, com Emil Ramann, especialista em solos tropicais. Isso induziu Vageler a produzir o primeiro livro sobre solos tropicais no mundo, publicado em alemão (VAGELER 1930), cuja repercussão promoveu uma rápida tradução para o inglês, por $\mathrm{H}$. Greene (VAGELER 1933).

Foi nesta fonte de consulta que se baseou, por exemplo, a nossa antiga Comissão de Solos para a caracterização mineralógica das areias dos solos paulistas (S.N.E.P.A. 1960); igualmente, no Paraná, MAACK (1950) classificou pioneiramente os materiais lateríticos e solos correlativos, com denominações como sialitos, feralitos, alitos, lateritos etc, conforme critério ilustrado em ESPINDOLA (2013).

Com a pedologia assimilada no seu nascedouro, CAMARGO \& VAGELER (1936) adiantaramse na notação A-B-C dos horizontes em um perfil de solo, embora esta prática tenha constituído, no momento, um caso isolado, pois os dados analíticos de solos continuaram a ser referidos a profundidades pré-fixadas, tal como na matéria de PAIVA NETTO (1947), da mesma seção de trabalho: 0-40, 40-80 e 80-150 cm para as Terras arenosas da Formação Bauru e Terras Massapé e Salmourão do Arqueano, ou até 150-250 e 250-350 cm para a Terra Roxa Pura da Província Magmática.

Além dessas denominações, muitas outras eram extraídas dos substratos e formações geoló- 
gicas, tal como empregado por FALLOU (1862); muitas daquelas foram incorporadas à linguagem científica, junto a nomes populares como "massapé" e "salmourão", com os quais SETZER (1941) se ocupou, constatando um teor de sílica do substrato mais elevado no primeiro, cuja matéria foi veiculada no primeiro número do periódico $\mathrm{Bra}$ gantia, até hoje editada pelo Instituto Agronômico de Campinas.

Com uma preocupação explícita voltada à gênese dos tipos de solos do Estado de São Paulo, MORAES RÊGO (1945) referiu-se aos solos eluviais de granitos e gnaisses (a expressão solos eluviais, na época, designava uma evolução a partir da rocha sotoposta); concomitantemente, ele empregava também as denominações massapé e salmourão, cujas expressões apresentavam, porém, diferentes significados nas distintas regiões brasileiras.

A designação Terra Roxa subtendia sempre um solo originário da alteração de rochas básicas; quando em mistura com materiais areníticos, era referida por Terra Roxa Misturada (VERDADE 1951). Os termos acabaram sendo incorporados na ciência e perdurou por muitos anos, tal como no difundido "Mapa dos grandes tipos de solos do Estado de São Paulo" elaborado pelo Instituto Agronômico da Campinas, o qual trazia na sua legenda: Salmourão e Massapé, Devoniano, Glacial, Corumbataí, Arenito Botucatu e Terra Roxa Misturada, Terra Roxa Legítima, Arenito Bauru, Terciário e Baixadas (PAIVA NETTO et al. 1951).

A ampliação das pesquisas em solos começou a se intensificar nas diferentes regiões brasileiras e os mapeamentos ganharam impulso mediante uma política de incentivo à irrigação iniciada na década dos anos 1940; tais levantamentos ocorreram, por exemplo, em Roças, no Ceará (AMARAL 1946), e na Baixada de Sepetiba, no Rio de Janeiro (FAGUNDES et al. 1950).

Em vários locais os levantamentos eram referidos por "agrológicos", como na Paraíba, (SOUZA MELLO 1950), ou "agrogeológicos", na Estação Experimental de Curado, em Pernambuco (COSTA LIMA 1951). Embora a expressão estudo pedológico tenha sido empregada para os solos da Estação Experimental de Campinas por PAIVA NETTO et al. (1953), VAGELER (1953), provavelmente em sua última publicação, empregou ainda levantamento agrogeológico para os procedimentos recomendados para esta execução.

$\mathrm{O}$ crescente contingente de investigações em solos acarretou a criação de órgãos oficiais de pesquisas voltadas a essas atividades, aos quais se somaram as escolas de agronomia da época. Cons- titui um marco significativo para a história brasileira dos solos a "I Reunião Brasileira de Ciência do Solo", no Rio de Janeiro, em 1947, quando se criou a "Sociedade Brasileira de Ciência do Solo", cujo avanço da pedologia deixava para trás a agrogeologia/agrologia.

A criação da Comissão de Solos do Serviço Nacional de Ensino e Pesquisas Agronômicas - S.N.E.P.A., do Ministério da Agricultura, reuniu experientes pesquisadores nacionais e expoentes estrangeiros em missões no País, como L. Bramão, J. Bennema e W.D. Sombroek, ligados à $\mathrm{FAO}$, além da participação ocasional de especialistas do calibre do norteamericano R.W. Simonson. O Instituto de Química Agrícola, com Leandro Vettori, interagiu estreitamente com aquela Comissão. O ensino de Solos começou a se desvincular de uma simples Química do Solo, ou de conteúdo similar, para ter a sua identidade própria (ESPINDOLA 2007, 2010).

Resultaram dessas novas disposições, levantamentos pedológicos dos nossos estados federativos, a começar pelo Rio de Janeiro e Distrito Federal (S.N.E.P.A. 1958), seguindo-se o do Estado de São Paulo (S.N.E.P.A. 1960), na escala 1: 500.000, com várias unidades de mapeamento constituídas por "Grandes Grupos" e suas "fases" ou "variações", já absorvendo os ditames de Dokuchaev na incorporação de denominações genéticas como latossolização, podzolização e, mais tarde, perfis com horizontes B latossólico e B textural.

Uma unidade de mapeamento com perfil com B textural sobre granito era designada Podzólico Vermelho-Amarelo Orto (Orto significando típico, argiloso); sobre argilito seria um Podzólico Vermelho-Amarelo variação Piracicaba e sobre arenito, Podzólico Vermelho-Amarelo variação Laras, aos quais se atribuía uma podzolização (na realidade, uma argiluviação, conforme ESPINDOLA 2013). Um Latosol Vermelho-Amarelo Orto (sobre granitos, gnaisses ou filitos) era designado fase rasa nos perfis pouco espessos, em vez de Orto, ou fase arenosa quando sobre arenitos, ou ainda fase terraço, sobre sedimentos terciários e quaternários alternados. Unidades que fugiam do conceito central dos grandes-grupos recebiam denominações particulares, como os Solos de Campos do Jordão, de altitudes elevadas (S.N.E.P.A. 1960).

Paralelos entre esta classificação e a de Fallou são nítidos quanto a determinados aspectos, principalmente com relação à importância conferida ao substrato geológico na geração dos solos. O designativo Variação para as unidades de mapeamento citadas encontra correspondência com Variedade 
da classificação alemã. Nomes de regiões ou localidades de ocorrência (Piracicaba, Laras, Campos do Jordão, Lins e Marília) são também elementos de convergência.

Cumpre ponderar que, de todos os fatores de formação responsáveis pela geração de solos bem desenvolvidos (Latossolos, Argissolos e Nitossolos), a influência marcante que predomina e persiste é a do substrato; um Latossolo Vermelho férrico é intuitivamente identificado com uma rocha básica subjacente, mesmo em perfis muito espessos e que comporte minerais alógenos na sua fração areia (ESPINDOLA 2009).

Igualmente, a admissão de uma aloctonia do material de origem não apaga a influência do substrato, o que levou QUEIROZ NETO (2008) a postular que a grande maioria dos solos é proveniente da alteração dos seus respectivos embasamentos. Assim não fosse, seria impossível explicar a diferente natureza dos solos de ampla extensão da Bacia Amazônica, supostamente entulhada por materiais das erosões andinas, segundo BENNEMA et al. (1962).

A rigor, dissolução, fragmentação e impactos da vida orgânica, mencionados por Fallou, podem coexistir como reações de intemperismo e como mecanismos pedogenéticos. TRICART \& CAILLEUX (1965) empregam "processos infrapedológicos" para modificações estruturais nos saprolitos e alteritos, o que parece se configurar no caso. Esta admissão enfraquece a alegação dos historiadores quanto à ausência da gênese naquela classificação pioneira, que o autor explicitou até no título do item - "Gênese do solo".

Além do mais, "Estratificação do Solo" estratos, segregação, sedimentação e inversões fazem subtender camadas justapostas, em analogia aos horizontes de um perfil, cuja noção é reforçada quando o cientista trata das "Diferenças entre os solos" e em "O conhecimento dos tipos de solos em particular". É muito possível supor a absorção de tais conteúdos pelo cientista russo, assim como, possivelmente, a sua inspiração em DARWIN (1838), com relação à notação A-B-C das camadas que este esboçara sem preocupações genéticas. Não haveria nenhum demérito em tais atitudes; ao contrário, representaria um legítimo atendimento à rogativa de Fallou quanto à dificuldade de criação de uma via nova: "que outros possam seguir e aperfeiçoar"; aceita esta possibilidade, Dokuchaev tê-la-ia atendido com a maestria que a sua obra reflete.

\section{CONSIDERAÇÕES FINAIS}

O cotejo entre a obra pioneira de FALLOU (1862) e a embrionária pedologia que emergiu no Brasil até os anos 1960 permite cogitar de uma encoberta contribuição que aquele pesquisador possa nos ter legado, via pesquisadores do Instituto Agronômico de Campinas, egressos da "escola Dokuchaev", onde privaram com cientistas de renome, como Emil Ramann (1851-1926), grande nome da pedologia alemã e conhecedor dos solos tropicais.

A classificação dos "Grandes tipos de solos do Estado de São Paulo" por pesquisadores daquela instituição, embasada nas litologias e formações geológicas paulistas (PAIVA NETTO et al. 1951), prestou-se, durante muitos anos, ao planejamento de práticas conservacionistas, desde o simples espaçamento entre curvas de nível e cordões em contorno até os cálculos e construções de terraços agrícolas, por vezes com obras de engenharia associadas (LIMA 1957).

Inúmeros foram os valiosos estágios e cursos de treinamentos em solos promovidos na antiga Fazenda Ipanema, SP, do Ministério da Agricultura, vários deles voltados a práticas conservacionistas e a máquinas e equipamentos agrícolas em conformidade com as peculiaridades dos "grandes tipos de solos” (ESPINDOLA 2008). Não há, pois, como deixar de conferir a Friedrich Albert Fallou o título de, pelo menos, "Cofundador da Pedologia", junto com V.V. Dokuchaev.

\section{AGRADECIMENTOS}

O autor agradece a Christian Feller, do Institut de Recherche pour le Développement - IRD, de Montpellier, França, pelo auxílio prestado à elaboração da presente matéria, bem como ao doutorando Marcelo dos Reis Nakashima, junto ao Departamento de Geografia da Universidade de São Paulo, na composição final do texto.

\section{REFERÊNCIAS BIBLIOGRÁFICAS}

AMARAL, E. 1946. Levantamento do mapa de solos da bacia de irrigação do açude público Santo Antônio de Ruças (Município de Ruças, Estado do Ceará). Revista Brasileira de Geologia, 8: 351-366.

ASIO, V.B. 2005. Comments on "Historical development of soil and weathering profile concepts from Europe to the United States of America". Soil Science Society of America Journal, 69: 571-572. 
BENNEMA, J.; CAMARGO, M.N.; WRIGHT, A.C.S. 1962. Regional contrasts in South American soil formation in relation to soil classification and soil fertility. In: NEW ZEALAND SOCIETY OF SOIL SCIENCE, INTERNATIONAL SOIL CONFERENCE, New Zealand, Transations, 2-15.

BLUME, H.P. 2002. Some aspects of the history of German soil science. Journal of Plant Nutrition and Soil Science, 165: 377-381.

BOULAINE, J.; MOREAU, R. 2002. Olivier de Serres et l'évolution de l'agriculture. L'Harmattan, Paris, Collection "Les Acteurs de la Science", $124 \mathrm{p}$.

BUOL, S.W.; HOLE, F.D.; McCRAKEN, R.J. 1973. Soil genesis and classification. Ames, Iowa University Press, 360 p.

CAMARGO, T.; VAGELER, P. 1936. Análise de solos. I. Análise física. Boletim Técnico do Instituto Agronômico do Estado de São Paulo em Campinas. 24: 1-81.

COSTA LIMA, J.W. 1951. Levantamento agrogeológico dos solos da Estação Experimental de Curado. In: REUNIÃO BRASILEIRA DE CIÊNCIA DO SOLO, 3, Recife, Anais, 545-570.

DARWIN, C. 1838. On the formation of mould. Proceedings of the Geological Society of London, 2: 274-576.

DARWIN, C. 1881. The formation of vegetable mould throug the action of worms with some observations on their habits. John Murray, London, $326 \mathrm{p}$.

DEMOLON, A. 1949. La génétique des sols et ses applications. Presses Universitaires de France, Paris, Collection “Que sais-je?” No 352, 135 p.

DOKUCHAEV, V.V. 1879. Short description and crytical analysis of the more important soil classifications. Trav. Soc. Nat. St. Petersburg, 10: 64-67 (Translation into English by the Soil Science Society of America - Soil Science Bibliography). Disponível em http:/ www.soils.org/. Acessado em 29 ago. 2014.

DOKUCHAEV, V.V. 1883. Russian Chernozem. In: V.V. Dokuchaev. Selected Papers, 1: 14419. (Translated into English by N. Kander - Jerusalem: Israel Program for Scientific Translations).

D'UTRA, G. 1897. Elementos de Agrologia. Fascículo I. $1^{\mathrm{a}}$ edição. Typographia Oriente, Santo Amaro-BA, 104 p.
EHWALD, E. 1960. Alexander von Humboldt und V.V. Dokuchaev. Albrecht-Thaer-Arquiv, 8: 561-582.

ESPINDOLA, C. R. 2007. História da pedologia: um resgate bibliográfico. In: UNICAMP, SIMPÓSIO DE PESQUISA E ENSINO DE CIÊNCIAS DA TERRA, 1/ SIMPÓSIO NACIONAL SOBRE GEOLOGIA NO BRASIL, 3, Campinas, Faculdade de Educação, CD Rom, 349-352.

ESPINDOLA, C.R. 2008. Retrospectiva crítica sobre a pedologia: um repasse bibliográfico. Editora da UNICAMP, Campinas, 400 p.

ESPINDOLA, C.R. 2009. Minerais alógenos em materiais de origem dos solos. In: SBCS, CONGRESSO BRASILEIRO DE CIÊNCIA DO SOLO, 32, Fortaleza, Resumos, 229 e Resumo Expandido em CD-ROM, 2 p.

ESPINDOLA, C.R. 2010. História do ensino de solos no Brasil. In: SIMPÓSIO BRASILEIRO DE EDUCAÇÃO EM SOLOS, 5, Curitiba, Resumos Expandidos, 2-4.

ESPINDOLA, C.R. 2013. Gênese e evolução das formações superficiais nos trópicos. Editora Beca, São Paulo, 368 p.

FAGUNDES, A.B.I.; VETTORI, C.N.; RAMOS, F. 1950. Contribuição para o estudo dos solos da Baixada de Sepetiba. In: SBCS, REUNIÃO BRASILEIRA DE CIÊNCIA DO SOLO, 1, Rio de Janeiro, Anais, 393-526.

FALLOU, F.A. 1855. Die Ackererden des Königsreichs Sachsen, geognostisch untersucht und klassifiziert. 2nd ed. G. Schönfeld's Buchlandlung, Dresden. ("Os solos aráveis do Reino da Saxônia e áreas adjacentes, com diagnósticos da geologia e classificação").

FALLOU, F.A. 1857. Anfangsgründe der Bodenkunde. G. Schönfeld, Dresden. ("Fundamentos da Ciência do Solo").

FALLOU, F.A. 1862. Pedologie oder allgemeine und besondere Bodenkunde. G. Schönfeld's Buchlandlung, Dresden, 487 p. ("Pedologia ou Ciência do Solo geral e especial").

FALLOU, F.A. 1875. Die Hauptbodenarten der Nord- und Ostsseländer des Deutschen Reiches naturwissenschaftlisch, wie landwirtschaftlich betrachtet. G. Schönfeld's Buchlandlung, Dresden. ("Os principais tipos de solos dos territórios Norte e Báltico do Império Alemão, considerados cientificamente"). 
FELLER, C.; BLANCHART, E.; JABIOL, B.; GREVE, M.H. 2005. Quand l'humus est à la origine de la pédologie. 1. Les travaux du forestier danois P.E. Müller (1840-1926). Étude et Gestion des Sols, 12: 101-122.

FELLER, C.; BLANCHART, E.; YAALON, D.H. 2006. Some major scientists (Palissy, Buffon, Täer, Darwin and Müller) have described soil profiles and developed soil survey techniques before 1883. In: B.P. Warkentin (ed.) Footprints in the soil: people and ideas in soil history. Amsterdam, Elsevier, 572 p.

FELLER, C.; AESCHLIMANN, E.; FROSSARD, E.; LUTZ, V. 2008. Friedrich Albert Fallou (1794-1877) et as "Pédologie". La Préface de l'ouvrage. Étude et Gestion des Sols, 15: 131-137.

HILGARD, E.W. 1860. Report on the geology and agriculure on the State of Mississipi. E. Banksdale State Printer, Jackson, 391 p.

HITCHCOCK, E. 1838. Re-examination of the economical geology of Massachussets. Dutton and Wentworth, State Printers, Boston, 139 p.

HUMBOLDT, A. von; BOUPLAND, A. 1879. Voyage aux régions équinoxiales du Nouveau Continent, fait em 1799, 1800, 1801, 1802, 1803 et 1804 . Paris, 12 vols.

HUNDESHAGEN, J.C. 1830. Die Bodenkunde in land-u. Forst Wirtschaftlicher Beziehung. Heinrich Laupp, Tübingen.

JOFFE, J.S. 1929. Soil profile studies: I. Soil as na independente body as soil morphology. Journal Series paper of the New Jersey Agricultural Exerimental Station, Dept. of Soil Chemistry and Bacteriology, p. 39-54.

JOHNSON, D.L. 1989. Surface stone lines, stone zones, artifact-manuport layers, and biomantles produced by bioturbation via pocket gophers (Thomas bottae). American Antiquity, 54: 370-389.

JOHNSON, D.L.; DOMIER, J.E.J.; JOHNSON, D.N. 2005. Reflexions on the nature of soil and its biomantle. Annals of the Association of American Geographers, 95: 11-31.

LIMA, O.F. 1957. Métodos de construção de terraços. Escritório Técnico de Agricultura ETA-M 2, Rio de Janeiro, 13 p.

MAAK, R. 1950. Notas preliminares sobre clima, solos e vegetação do Paraná. Boletim Geográfico, 84: 1401-1487. (Tese apresentada em Arquivos de Biologia e
Tecnologia em 1948, aprovada na II Reunião Brasileira de Ciência do Solo, em Campinas, em 1949).

MORAES RÊGO, L.F. 1945. Considerações preliminares sobre a gênese e distribuição dos solos do Estado de São Paulo. Boletim Geográfico, 27: 351-376.

PAIVA NETTO, J.E. 1947. Considerações gerais sobre a situação dos elementos químicos $\mathrm{K}$, $\mathrm{Ca}, \mathrm{Mg}, \mathrm{P}$ e Azoto nos três tipos de solo de onde se assenta a nossa lavoura cefeeira. Colheitas e Mercados, 3: 6-8.

PAIVA NETTO, J.E.; CATANI, R.A.; KÜPPER, A.; MEDINA, H.P.; VERDADE, F.C.; GUTMANS, M.; NASCIMENTO, A.C. 1951. Observações sobre os grandes tipos de solos do Estado de São Paulo. Bragantia, 11: 227-253.

PAIVA NETTO, J.E.; KÜPPER, A.; CATANI, R.A.; MEDINA, H.P. 1953. Estudo pedológico da Estação Experimental de Campinas. In: SBCS, REUNIÃO BRASILEIRA DE CIÊNCIA DO SOLO, 2, 1949, Anais, 341-342.

PÉDRO, G. 1984a. La pédologie cent ans après la parition du "Tchernozem russe" de B.B. Dokuchaev (1883-1983). Science du Sol, 2: 81-92.

PÉDRO, G. 1984b. La pédologie cent ans après (1883-1893) - Conclusions. Science du Sol, 2: $183-184$.

PLAISANCE, G.; CAILLEUX, A. 1958. Diccionaire des sols. La Maison Rustique, Paris, $604 \mathrm{p}$.

QUEIROZ NETO, J.P. 2008. Relações entre as vertentes e os solos: uma revisão. In: UGB, SIMPÓSIO NACIONAL DE GEOMORFOLOGIA, 7, Belo Horizonte, Resumos, 179.

RAMANN, E. 1905. Bodenkunde. Springer, Berlin, 431 p.

RICHTOFEN, F.F. von, 1886. Fürer für Forscungsreisende. Anleitung $\mathrm{zu}$ über Gegenstände der physischen Geographie und Geologie. Verlag R. Oppenheim, Berlin, 745 p. ("Guia para os exploradores. Instruções para observações diretas de objetos da geografia física e geologia").

SALTINI, A. 1984. Storia dele scienze agrarie: dalle origini al renascimento. Edagricole, Bologna, $530 \mathrm{p}$. 
SÃO PAULO. 1911. Primeiro Congresso de Ensino Agrícola, São Paulo, 1911. Typographia Brazil - Rothchild Loureiro \& Cia., São Paulo, 225 p.

SCARPONI, F. 1949. Il concetto della fertilità nella sua evoluzione attraverso $\mathrm{i}$ tempi. Milano, $16 \mathrm{p}$.

SCHROEDER, D. 1988. Alexander von Humboldt und die Bodenkunde - memoriam Ernst Ehwald. Archiv für Acker- und Pflanzenbau Bodenkunde, 32: 3-9 ("Alexander von Humboldt e a ciência do solo").

SETZER, J. 1941. As características dos principais tipos de solos do Estado de São Paulo. Bragantia, 1: 255-359.

SIMONSON, R.W. 1968. Concept of soil. Advances in Agronomy, 20: 1-47.

S.N.E.P.A. - SERVIÇO NACIONAL DE ENSINO E PESQUISAS AGRONÔMICAS, COMISSÃO DE SOLOS. 1958. Levantamento de reconhecimento dos solos do Estado de Rio de Janeiro e Distrito Federal. Rio de Janeiro, 350 p. (Boletim, 11).

S.N.E.P.A. - SERVIÇO NACIONAL DE ENSINO E PESQUISAS AGRONÔMICAS, COMISSÃO DE SOLOS. 1960. Levantamento de reconhecimento dos solos do Estado de São Paulo. Rio de Janeiro, Boletim 12, 462 p.

SOUZA MELLO, F.E.S. 1950. Estudo agrológico da bacia de irrigação do açude público "São Gonçalo", na Paraíba. In: SBCS, REUNIÃO BRASILEIRA DE CIÊNCIA DO SOLO, 1 , Rio de Janeiro, Anais, 288-389.

SPRENGEL, C. 1837. Die Bodenkunde oder die Lehre vom Boden nebst einer vollstaendigen Anleitung zur chemischen analyse der Ackererden. I. Müller, Leipzig, 450 p. (“A ciência do solo ou do ensino do solo, bem como um guia completo para a análise química dos solos aráveis").

TANDARICH, J.P.; DARMODY, R.G.; FOLLMER, L.R.; JOHNSON, D.L.
2002. Historical development of soil and weathering profile concepts from Europe to the United States of America. Soil Science Society of America, 66: 335-346.

TRICART, J.; CAILlEUX, A. 1965. Traité de géomorphologie. SEDES, Paris, Tome 1, 305 p. et tome $5,322 \mathrm{p}$.

VAGELER, P. 1930. Grundis der tropischen und subtropischen Bodenkunde. Verlagsgesellschaft fur Ackerbau, Berlin, 216 p.

VAGELER, P. 1933. An introduction to tropical soils. MacMillan, London, 240 p. (Grundis der tropischen und subtropischen Bodenkunde. Verlagsgesellschaft fur Ackerbau, Translated by $\mathrm{H}$. Greene).

VAGELER, P. 1953. Princípios e métodos modernos do levantamento agrogeológico global em grandes áreas virgens. In: SBCS, REUNIÃO BRASILEIRA DE CIÊNCIA DO SOLO, 4, Campinas, Anais, 275-283.

VERDADE, F.C. 1951. Estudo da variabilidade dos nitratos num solo tipo Terra Roxa Misturada. $I n$ : SBCS, REUNIÃO BRASILEIRA DE CIÊNCIADO SOLO, 3, Recife, Anais, 129-158.

WILDE, S.A. 1963. Pioneers of soil scence - a British view. Soil Science, 97: 258-359.

YARILOV, A.A. 1904. Francis Albert Fallou, the founder of soil Science. Potchovovedenie, $\mathrm{N}^{\circ}$ 2. (Tradução do periódico russo pela Soil Science Society of America - Soil Science History Bibliography, organizada por Eric Brevik). Disponível em http://www.soils.org. Acessado em 28 ago. 2014.

YARILOV,A.A. 1910. Carl Linnaeus and Soil Science. Potchovovedenie $\mathrm{N}^{\circ}$ 3. (Tradução do periódico russo pela Soil Science Society of America-Soil Science History Bibliography, organizada por Eric Brevik). Disponível em http://www.soils. org. Acessado em 28 ago. 2014.

YARILOV, A.A. 1936. Charles Darwin - the founder of Soil Science. Potchovedenie, 4: 17-23.

\section{Endereço do autor:}

Carlos Roberto Espindola - Faculdade de Engenharia Agrícola, Universidade Estadual de Campinas UNICAMP, Avenida Cândido Rondon, 501, Cidade Universitária Zeferino Vaz, Distrito de Barão Geraldo, CEP: 13.083-875, Campinas, SP. E-mail: crobertoespindola@gmail.com 